\title{
Ecological-Geobotanical Monitoring of Forest Use (Some Methodological Aspects)
}

\author{
Alexander Sizykh1, Alexey Shekhovtsov² \\ ${ }^{1}$ Siberian Institute of Plant Physiology and Biochemistry, Russian Academy of Sciences, Irkutsk, Russia \\ ${ }^{2}$ Institute of Geography, Siberian Branch of Russian Academy of Sciences, Irkutsk, Russia \\ Email: alexander.sizykh@gmail.com
}

How to cite this paper: Sizykh, A. and Shekhovtsov, A. (2017) Ecological-Geobotanical Monitoring of Forest Use (Some Methodological Aspects). Open Access Library Journal, 4: e3317.

http://dx.doi.org/10.4236/oalib.1103317

Received: December 19, 2016

Accepted: January 9, 2017

Published: January 12, 2017

Copyright $\odot 2017$ by authors and Open Access Library Inc.

This work is licensed under the Creative Commons Attribution International License (CC BY 4.0).

http://creativecommons.org/licenses/by/4.0/ c) (i) Open Access

\begin{abstract}
Setting of forms and methods for forest use must be based on assessment and forecast characteristics of forests modern state taking into account probable trends of their formation (or reconstitution) on the base of the analysis of modern physical-geographic conditions on a concrete territory. A very efficient method for this can be an ecological mapping monitoring of forest use with outlining of a series of ecological-geobotanic maps and express schematic maps of the state of forest communities for a concrete time between forests taxation periods; these are often 15 - 25-years (sometimes more) their components. This work is considering as theoretic aspect in discution for establishing some new methodical approaches for organization of forestry at all. According to this, we have to say that use its position in forestry will be more objective and allow to preserve natural basis of forest use and its restoration. Next step is using that approaches on the practice.
\end{abstract}

\section{Subject Areas}

Forestry, Biogeography

\section{Keywords}

Ecological-Geobotanic Maps, Express Schematic Maps, Forests Taxation, Monitoring, Lake Baikal Basin

\section{Introduction}

The maps of environmental systems with different thematic specialization allow to obtain information on the state of any environmental component and to characterize it for a definite time period and territorial confinedness. Mapping material for any specialization is one of essential methods and ways of observations of processes in natural systems in time and space. 
The statistic information obtained by mapping reflects modern situation (express-information) of the state of a concrete component in geosystems. The specifics of physical-geographic conditions and the region history, as well as anthropogenic impact for a concrete time period are taken into account. It is know that the importance of ecological problems rises due to poorly studied structural-dynamic and functional properties of concrete components in the natural systems, of the "laws" of their development under definite condition and of forms of their use when the available information is mainly descriptive.

The vegetation can be described during several decades, but if we have no materials reflecting visually these or those structural-dynamic parameters of the phytocenoses of any level of their organization, there are some problems to use such information to find out which consequences occurred or will occur from any concrete form or type of a vegetation site use in time and space. The descriptive material is often superficial and not always convenient for analytical constructions, and sometimes it results in erratic conclusions.

\section{Results}

Regarding forest use problem in the Baikal Region, we have to state that maps documenting the state of forests with information closely connected with the environmental situation appeared in early 1950ies (first forest taxation schematic maps). The accounting of forest resources and organization of forest exploration was based on the assessment of forests by their composition, age and growth class. The majority of them are schematic maps of quite economic characteristics of timber stands of statistical character serving for indication where and how much wood could be taken at minimal expenses.

Forests taxation maps from 1970ies present such characteristics, but there is already more detailed information about the character of spatial differentiation of timber stands taking into account their stocks and possible amounts of wood trial. Forests taxation maps of 1985 represent practically reproduction of the structure of maps from 1970ies, but with larger fractioning of forest tax a strata and quarter network. We can notice here that even at first approximation, there are some divergences of outlined areas for 35 years at revised account. This circumstance allows to suppose that the assessment of wood stocks (including trial amount) was done from the viewpoint of existing of timber stands convenient for cutting on the base of accounting materials for a concrete period. I.e., each accounting period was a base for definition of cutting amount, while the state of timber stands of the accounted area after the cutting was not taken into account at all. Consequently, timber stands states for accounting time was assessed, and it was unnecessary to have information about processes occurring during the forest reconstitution under concrete conditions of a concrete area between accounting periods. We can state here that lack of information on the dynamics of forest reconstitution for such a long period results in the situation when one cannot assess forests from natural and economical viewpoint at the next taxation. 
At new taxation, we have as well to take into account some other characteristics of timber stands, with other criteria, although in the same region, in the same forests and with the same use form (cutting category). Essentially, the starting point of the assessment of the real situation in the potential cutting sites shifts to decades. So, subsequent forest taxations, and by their character, this was "copying" of forests taxation maps, were based in the region on the previous criteria of the assessment of the state of forest communities [1] [2], only aerophotographs data were used in more detail [3] [4] [5]. However, marking network for indication of deciphering features of the state of forests on the maps does not include often the whole spectrum of the diversity of spatial and vertical stratigraphy of forests and of conditions at the sites of their growing.

However, having mapping materials obtained while analyzing the landscape structure of the territory covered with forests [6] of intermediate (between accounting periods) character, we will be able to assess the state of forest areas more accurately. We will be able as well to characterize their development, to assess the real stocks and amounts of cuttings, to find out where they are possible and where quite not in order to keep the natural base for reconstitutional abilities of the territory. This is possible by making express schematic maps of the timber stands state concerning dynamics for different time periods-for 5, 10, 15, etc. years. Such mapping materials (situational schematic maps of forests taxation) between the periods of complete forests taxations stated by legislation are able to reflect concrete statistical and temporal characteristics of forests formation at any territory with time.

It is as well to notice here that much information on forests state can be obtained from ecological-geobotanic maps of large scale (such scales as 1: 5000 - 1: 25,000 ), as they include statistical data and reflect the peculiarities of structural-dynamic organization of forest communities simultaneously during their development under definite physical-geographic conditions while assigning or having an assigned regulation of forests exploration form for a concrete period. Although the assignement of dynamic parameters for ecological-geobotanic mapping is quite tentative and is based on some knowledge of a researcher about "the object", these parameters can be (and are) a base for the assessment of "the object" state for determination and assignement of recommendation for any nature management forms, including forestry.

\section{Discussion}

Due to this fact, ecological-geobotanic monitoring of forest use with express schematic mapping (situational one) and use of ecological-geobotanic maps of different scale for concrete forest sites will allow to approach more impartially to determination of forms and tipes of forests exploration assessing the forests states in real time regime rather than to use forest taxation data obtained long ago. At the same time, using such approach in the organization of forest resources use, we will help to keep not only the raw wood, but also natural forests reconstruction potential at a concrete territory. The links within and between 
ecosystems will be kept as well. They provide stability in the functioning of forest community in a system and, consequently, the stability and long duration in the user and reconstitution [7] [8] [9] [10] [11] of forest resources.

Periodicity of observations, which provide basic information for ecologicalgeobotanic and express schematic mapping (situational ones) may depend on:

1-The character of physical-geographic conditions in the forest use region;

2-Established before forms and regimes of resources use;

3-Structure and dynamics of natural systems at a definite type or form of a resource use and

4-Analysis of situation at which organization of this or that form or type of resource use was performed from historical viewpoint.

\section{Conclusions}

There are a lot of opinions and too many definitions about what sustainable forestry is. Naturally, each opinion and definition of "what is meant" by everybody who is talking about it is true. We have to think about the needs of people and about how to preserve nature as well. This is also true.

Unfortunately, most opinions and definitions of what sustainable forestry are based on what people can manage of nature. But we have to find the answers to the following questions: How much do we have the forests? And how much are we allow to use of forests?

We have been changing ecosystems and type of forests and we can continue so, but only toward its simplification or degradation. We can speak about sustainable forestry very much, but we cannot demand from nature to do more than it will be able to do, of cause. The Baikal region is a good example for that. The question is to what extent sustainable forest use is sustainable. Right now we look like people going upstairs leading down. And we must change methods of forest use on the basis new methodical approaches in forestry at all.

\section{References}

[1] Vashchuk, L.N. (1987) About Perfect of the Assessmention of the Forest Use Size. Forestry, 3, 56.

[2] Vashchuk, L.N. (1994) Forest of Irkutsk Region. Irkutsk: Publishing by Irkutsk Forest Manadgement. $111 \mathrm{p}$.

[3] Wagner, W., Luckman, A., Vitmeier, J., et al. (2003) Large-Scale Mapping of Boreal Forest in Siberia Using ERS Tandem Coherence and JERS Backscatter Data. Remote Sensing of Environment, 85, 125-144. https://doi.org/10.1016/S0034-4257(02)00198-0

[4] Vashchuk, L.N. and Shvidenko, A.Z. (2006) Dynamics of Forest Land of Irkutsk Region. Publishing by "Printing Plant of Irkutsk Region”, Irkutsk, 392 p.

[5] Vashchuk, L.N. (2014) Irkutsk Forestry Is 120 Years Old: Stages of Forest Management Development. Forward Ltd. Publishing House, Irkutsk, 376 p.

[6] Ziganshin, R.A. (1997) Taxation of Mountain Forests on the Natural Base. Publishing House of V.N. Sukachev Forest Institute of RAS SB, Krasnoyarsk, 203 p.

[7] Hummel, R. and Sizykh, A. (1997) Sustainable Development of Forestry as a Way to 
Preserve the Natural Basis of Forestry. Sustainable Forests: Global Challenges and Local Solutions. The Haworth Press, Inc., New York-London, 53-60.

https://doi.org/10.1300/j091v04n03 06

[8] IPCC (2000) Land Use, Land-Use Change and Forestry. A Special Report of the IPCC Cambridge Press, Cambridge, 377 p.

[9] Global Forest Resources (2001) Assessment 2000. Main Report. FAO Forestry Paper 140, Rome, 479 p.

[10] Boethihartono, A.K. and Sayer, J. (2012) Forest Landscape Restoration: Restoring what and for Whom? Forest Landscape Restoration. Integrating Natural and Social Sciences. Springer Dordrecht Heidelberg, New York-London, 309-324.

[11] Shutov, I.V. (2015) About Forest Taxation and Organization of Forest Use of Russia. Forestry, 2, 8-15.

Submit or recommend next manuscript to OALib Journal and we will provide best service for you:

- Publication frequency: Monthly

- 9 subject areas of science, technology and medicine

- Fair and rigorous peer-review system

- Fast publication process

- Article promotion in various social networking sites (LinkedIn, Facebook, Twitter, etc.)

- Maximum dissemination of your research work

Submit Your Paper Online: Click Here to Submit

Or Contact service@oalib.com 